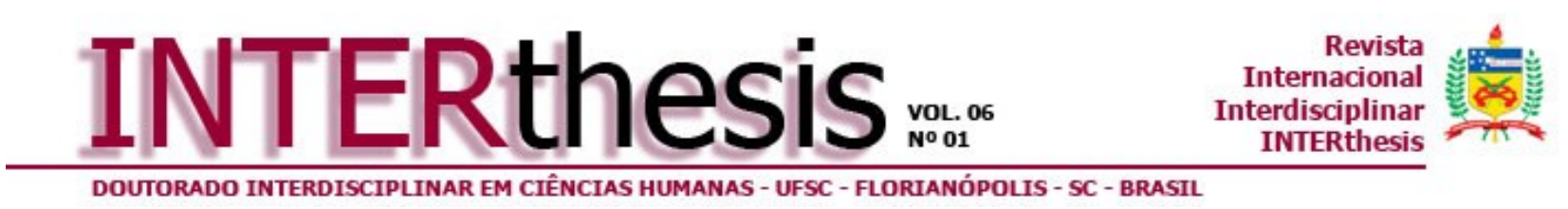

RESENHA - REVIEW - RESEÑA

\title{
CRÍTICAS MINIMALISTAS E CONTUNDENTES
}

MINIMALIST AND CONTUSIVE CRITIQUES

\section{CRITICAS MINIMALISTICAS Y CONTUNDENTES}

\section{Por: Leandro Oltramari}

Professor de Psicologia da Universidade do Sul de Santa Catarina e Universidade do Valedo Itajaí, Doutor em Ciências Humanas pelo Programa de Pós-Graduação Interdisciplinarem Ciências Humanas (PPGICH/UFSC). Mestre em Psicologia (UFSC). E-mail: leandrooltramari@gmail.com

LEIS, H R; ASSMANN, S. J. Críticas minimalistas. Florianópolis: Insular, 2007. $191 \mathrm{p}$.

Esta obra é o resultado de um trabalho integrado, de dois professores da Universidade Federal de Santa Catarina, sobre temáticas da política e filosofia, através de uma publicação periódica, na cidade de Florianópolis, em Santa Catarina. A partir dos artigos publicados em um periódico, os pesquisadores organizaram a obra intitulada Críticas Minimalistas.

Os autores Héctor Ricardo Leis e Selvino José Assmann, reconhecidos nacional e internacionalmente, propõem-se, nesta obra, a realizar discussões que sejam acessíveis a um público não somente acadêmico. No entanto, não é por isso que seus textos são isentos de aprofundamento teórico. Eles versam principalmente sobre discussões de Política, Sociologia e Filosofia. Héctor Leis é sociólogo, com mestrado e doutorado em Filosofia pela PUC do Rio de Janeiro e é autor de diversos textos e livros em várias áreas, principalmente no âmbito de questões relacionadas a meio ambiente e condição humana. Selvino José Assmann é filósofo, com mestrado e doutorado pela Pontifícia Universidade Lateranense de Roma, autor de várias obras e tradutor de textos com temáticas como Ética, Política e Antropologia Filosófica. 
A obra é dividida em quatro partes: Brasil, Mundo, Condição humana e Relendo os clássicos. Em cada uma delas, os autores entram em searas bastante instigantes sobre a atualidade dos assuntos abordados. Atualidade talvez seja uma das características dos seus textos, cujos temas são tratados de forma direta, sempre relacionados a autores clássicos da política e filosofia mundiais.

Na primeira parte, Brasil, os textos são assinados quase sempre em parceria. Nas duas exceções, Héctor Leis assina um texto exclusivamente e divide, com Samantha Buglione, a autoria de outro, Bussunda, PCC e a crise do pensamento. Nessa parte do livro, são abordadas temáticas centrais do pensamento político brasileiro, direcionando suas análises para a forma banalizada com que estamos vivendo o terror urbano no país e para o sofrimento de uma crise de autoridade, em detrimento de uma democracia enfraquecida. Sobre a violência, Leis é polêmico em seu texto, quando discute que hoje existe uma perspectiva ideológica a qual justifica que a violência tem sido causada pela pobreza. Assim, ele critica que a sociedade inteira deva ser responsabilizada por esses males sociais. Para o autor, a violência e o terror têm relação com uma falta de compreensão sobre a democracia e com a falta de punição dos culpados.

Com certeza, isso não deixa de ser realidade, mas, ainda que tais questões sejam pertinentes, o texto não esclarece onde fica a responsabilidade de um Estado que muitas vezes é totalitário e que trata de forma desigual os seus cidadãos.

As temáticas tratadas no livro são variadas. Por exemplo, nessa parte da obra, os autores comentam de forma crítica o tema do futebol, algo tão caro aos brasileiros. Revelam como o futebol ganhou adeptos e se tornou um alienante esporte para as pessoas no Brasil. Apesar de o enfoque não ser uma novidade, eles mencionam um fato interessante: a forma como foi gerenciada a derrota brasileira na Copa de 2006. Além disso, relacionam tal fato a um problema crônico no Brasil, que é a falta de prestação de contas - em inglês, accountability -, feita sine qua non em um sistema democrático. Vale lembrar que eles publicaram o texto antes mesmo do escândalo dos cartões corporativos. Seria possível até dizer que a vida imita a arte: como se os autores não tivessem se baseado em algo tão comum no Brasil, que é a falta de prestação de contas para a sociedade em geral.

Discutindo sobre a segurança pública no Brasil, como é característica desses autores, é utilizada uma ironia refinada, mas contundente, quando comparam a 
segurança do Rio de Janeiro à da cidade de Bagdá, no Iraque. Relatam que em Bagdá a violência tem motivações com alvos definidos, enquanto que, no Rio de Janeiro, não há objetivo político na luta. Trata-se de uma violência sem foco. Todos são o alvo. A partir daí, criticam as declarações da ministra Ellen Gracie, que foi vítima da violência do Rio de Janeiro. Os autores revelam que ela também banalizou a violência que foi cometida.

Na segunda parte do livro, intitulada Mundo, os autores discutem temas que vão desde o meio ambiente até o conceito de interdisciplinaridade. Percebe-se uma preocupação frequente, em toda a obra, em relação à democracia e àquilo que é identificado como "populismo". Esse populismo, inclusive, aparece diversas vezes como uma das principais ameaças ao Estado democrático de direito. E não há como negar que essas linhas fazem pensar, por exemplo: como se pode ter uma democracia forte no Brasil sem que haja uma preocupação com o que os autores chamam de "populismos nacionalistas"? Trata-se de uma crítica clara ao que vem acontecendo na política da América Latina.

Ao "populismo" bolivariano, Leis dedica várias páginas, ressaltando o perigo que ele representa para a democratização da América Latina. Trata do risco de um elogio ao populismo e de uma queda do processo de democratização em virtude disso. E ressalta que a democracia não pode ser "sedutora". Vale salientar, no entanto, que não se pode disfarçar em suas críticas o tom liberal que elas por vezes tomam. Ainda assim, tais críticas são importantes para um continente que sofreu e muito em decorrência de ditaduras por longas décadas. A este respeito, ele afirma: "quanto mais fracas as instituições de um país, mais exposto ele fica à aventura populista" (p. 70). Tem-se aqui uma clara crítica a Hugo Chaves e Evo Morales; a esquerda latino-americana é alvo constante nas críticas do professor Leis. Ele revela que o militante de esquerda direciona-se por motivações existenciais, tendo pouca capacidade crítica sobre uma análise política mais ampla dos fenômenos que o circundam. Fala sobre quatro tipos de esquerda: a esquerda revolucionária cubana, a democrática chilena, a populista e a revolucionária de Chavez e Morales - os "bad boys" da política latino-americana. Sobre a esquerda brasileira, suas críticas são menos contundentes que a realizada a respeito dos presidentes da Venezuela e da Bolívia. O foco das críticas se dá, principalmente, no descompasso existente entre o pensamento marxista e tudo o que aconteceu nos estados-nação a partir de suas 
implementações. Leis ainda "provoca" aqueles que seguem este pensamento, afirmando que isso consiste em uma "perda de tempo". Vale dizer que esse tom crítico, por vezes com forte cunho liberal, não deixa de ser instigante mesmo a quem discorde de suas posturas. Esse tom do discurso é recheado de argumentos que estimulam o pensamento do leitor. Nada mais importante do que uma leitura que ajude a repensar os fenômenos circundantes à nossa sociedade.

Contudo, nem só de política essa segunda parte é feita. Também são apresentadas idéias sobre temáticas mais acadêmicas, como a interdisciplinaridade. Os pesquisadores, que já foram coordenadores do Doutorado Interdisciplinar em Ciências Humanas da Universidade Federal de Santa Catarina, além de autores de textos sobre esse tema, falam da sua importância para o universo acadêmico brasileiro. No entanto, não deixam de mostrar as dificuldades para a sua implementação.

Encerrando a parte três, é abordada a discussão ambiental. Nessa parte, os autores anunciam as tão propaladas mudanças climáticas, revelando que os países aproveitaram a globalização econômica, mas pouco se importam com as questões ambientais. Segundo eles, é o que ocorre na China, por exemplo. Essa discussão, sobre o controle ambiental e a aliança entre países que estão em desenvolvimento, é complexa.

Sobre a parte três, intitulada Condição humana, os autores voltam para atualizar temas já desenvolvidos na obra Crônicas da Pólis, publicada em 2006. Nessa parte, abordam temáticas como a religião, comentando inicialmente a morte do Papa João Paulo I, para compreender o papel da Igreja no século XXI.

Tratam ainda do dilema da natureza humana, questionando o relativismo motivado pelas discussões culturalistas, por exemplo, no que se refere a uma essência humana. No entanto, mesmo trazendo a importância das pesquisas genéticas e dando a entender que existe uma natureza humana atrelada à nossa bagagem genética, os autores fazem questionamentos sobre o rumo eugenista que tal discussão pode tomar. Vale dizer que eles, quando enfrentam essa questão, vão em sentido contrário ao das discussões pós-estruturalistas realizadas por autoras reconhecidas no campo de gênero, como Judith Butler (2003) que, através de sua discussão sobre performatividade, desconstrói a idéia de uma essência humana, principalmente quando atrelada ao gênero. 
Sobre temáticas como o mal, os autores revelam que ele surge aos nossos olhos todos os dias. Aqui não há como não lembrar do "caso Isabela", no qual os próprios pais foram acusados da morte da filha jogada pela janela do prédio em que moravam. Os autores citam Hannah Arendt, para dizer como existe uma aceitação do mal no nosso cotidiano ou como temos interesse em assisti-lo pela televisão. Pode-se verificar que esta discussão dos autores está bem relacionada à falecida ensaísta norte-americana Susan Sontag (2003) e sua obra Diante da dor do outro. Nesta, de forma histórica e muito interessante, ela aborda esse mórbido desejo de assistir ao sofrimento alheio. Isto fica aparente principalmente quando se percebe o quanto os meios de comunicação exploraram a temática do "caso Isabela" para alcançar altos índices no IBOPE.

Ao falarem sobre amizade, os autores já iniciam sutilmente tratando da "liquidez" do mundo moderno e fazem uma clara alusão a Zygmunt Bauman. Dizem que as utopias políticas excluíram a amizade como intervenção política. Fazem a crítica a partir daquilo que denominam de "ética da amizade" (p. 128). Partindo principalmente do pensamento de Foucault, entendem que amizade é querer fazer bem ao outro, sobretudo no caso da amizade que tem um sentido único, e não por interesse. Vale o registro do conceito de amizade: "amigo não é aquele que cuida do outro, nem quem se faz cuidar pelo outro, mas aquele que estimula o outro a cuidar de si mesmo, enquanto é estimulado pelo amigo que faça o mesmo consigo" ( $p$. 128). Esta consiste numa prática interessante de ser pensada, em dias de tão pouca alteridade.

Para isso, são discutidos aspectos da espetacularização da intimidade, identificada pelos autores, por exemplo, em programas que a exploram, como o BBB - o Big Brother Brasil. Eles afirmam que esse programa dá a sensação de poder acessar a intimidade do outro, sem ter a intenção de mostrar a sua própria. Dizem que isso é uma reafirmação do eu. Os autores, com essa discussão, ainda revelam a necessidade de se questionar até que ponto a intimidade pode ser conduzida pura e simplesmente pela reflexividade da modernidade como projeto teórico e político.

$\mathrm{Na}$ quarta e última parte do livro, o professor Selvino Assmann faz uma tradução de quatro textos, de Machiavel, Olympe de Gouges, Péricles e Hannah Arendt. Desses textos, talvez o que chame mais a atenção é a Declaração dos direitos da mulher e da cidadã, de Olympe de Gouges, publicado originalmente em 
1791. Essa autora defendeu os direitos das mulheres, depois da Revolução Francesa de 1789. Mesmo apoiando a revolução, foi morta decapitada dois anos depois. Vale dizer que seu texto é referência pela atualidade de suas reivindicações.

O texto de Leis e Assmann traz várias contribuições, mas talvez a principal delas seja a de provocar um estranhamento da vida cotidiana a partir de temáticas atuais, atrelando-as a discussões teóricas profundas. É uma leitura agradável, já que os textos abordam diversos assuntos em poucas páginas. Esta obra pode ser lida tanto por pessoas que estão iniciando nas discussões políticas e filosóficas, quanto por pessoas que já se encontram em níveis mais avançados de estudo. Portanto, talvez o título pudesse ser um pouco mais arrojado, pois as críticas são mais profundas do que ele propõe.

\section{Referências}

SONTAG, S. Diante da dor do outro. São Paulo: Companhia das Letras, 2003.

BUTLER, J. Problemas de gênero. Rio de Janeiro: Civilização Brasileira, 2003.

LEIS, H; ASSMANN, S. Crônicas da Pólis. Florianópolis: Fundação Boiteux, 2006.

Resenha:

Recebida em: 02/02/2009

Aceita em: 18/06/2009 